\title{
Nephrology Workforce in India - A Fellow's Perspective
}

\author{
Sandeep G. Huilgol*
}

Narayana Hrudayalaya, Multispecialty Hospital, Bangaluru, India

\begin{abstract}
The interest in nephrology career has been declined in the west as per the recent data available from national residency match program; in contrast Nephrology continues to attract applicants in India. This short paper describes the features of Nephrology that continue to make it an attractive specialty for physician-trainees in India, and how some of these features can be exported to the United States.
\end{abstract}

Keywords: Fellowship training, interventional nephrology, nephrology workforce.

\section{INTRODUCTION}

The interest in nephrology career has been declining in the west as per the recent data available from national residency match program [1] but in contrast Nephrology continues to attract applicants in India.

The following are the key reasons why Nephrology remains a highly preferred career path for medicine residents in India:

\section{PROFESSIONAL SATISFACTION}

Nephrology is a field of medicine that is not compartmentalized and embodies the knowledge and experience gained during Internal medicine residency. The fellows do not view the 3-year internal medicine training as futile. Moreover, a Nephrology fellow in India is trained in interventional procedures like tunneled catheter insertions, Ultrasound guided renal biopsies and peritoneal dialysis catheter insertions providing timely care and professional satisfaction of treating their patients without dependence on colleagues from radiology or surgery.

\section{SOCIAL SATISFACTION}

Being actively involved in treating patients who are economically underprivileged in renal clinics provides a great sense of fulfillment. Further getting involved in community work such as driving awareness programs among general public and general practitioners, academic detailing and training augments social satisfaction.

\section{FINANCIAL COMPENSATION AND JOB PROSPECTS}

Financial compensation although not as much as some other specialties is an important aspect for internal medicine graduate in opting for a career in nephrology. The advent of

*Address correspondence to this author at the Narayana Hrudayalaya, Multispecialty Hospital, Bangaluru, India; Tel: +91-9611517633;

E-mail: drsandeephuilgol@yahoo.co.in interventional nephrology in India further augments the business aspect of nephrology. Interventional procedures have been incorporated in to the basic nephrology-training curriculum. The overall economic growth trajectory of the country, patient awareness and growing support from various governmental and non-governmental funding sources for dialysis care in India, has increased the demand for nephrology workforce.

\section{RESEARCH OPPORTUNITIES}

In India, lack of resources and limited emphasis during the undergraduate training is often a deterrent to pursue a research career. A 3-year nephrology fellowship is universal in India and offers an excellent opportunity to pursue a research interest. Unlike in the United States, most training programs offer a 2-year track. A nephrology fellow is required to complete a research project to be eligible to take the certifying board examination.

\section{PROPOSED STRATEGIES TO INCREASE INTEREST IN NEPHROLOGY}

The below mentioned are the ideas in which author feels the interest in Nephrology can be increased after discussion with colleagues and other fellows

1. Increase the exposure of medical students to the field and scope of Nephrology at a very early stage. McMohan GM et al. [2] have shown that restructuring the curriculum focusing on problem based learning and demystifying the fear of fluidelectrolyte and acid-base disturbances will generate interest in nephrology.

2. Involving medicine residents in community-based programs targeting patient education and awareness, prevention and epidemiological studies would help them understand the current needs of the society and empathize them to take Nephrology.

3. The world has become a global village. A student exchange program between developed and developing countries would expose the future generation to better understand the disease spectrum, difference in 
practices, resource allocation and social and economic challenges. An opportunity to learn and help mankind on a bigger platform may kindle the philanthropic values of a physician. An opportunity to learn and teach at a global level may be an important aspect of building leadership skills.

4. Including interventional procedures such as tunneled central venous catheter insertion, kidney biopsy and peritoneal dialysis catheter insertion would help them provide not only timely care but also support the business of nephrology [2,3]. The satisfaction of providing complete care to their patients is the key driving force in India compared to their counterparts in the United States. The dependence on their colleagues from other field often makes it uninteresting and cumbersome to practice nephrology. Again a leadership role in the management of complex and challenging renal patient is rewarding.

5. Increasing the duration of training, if possible, will allow fellows to get sufficient time to get involved in research projects.

6. The author agrees with the idea of integrating critical care medicine and Nephrology [4] so that those interested in critical care can get motivated to even consider Nephrology.

7. Likewise, developing fields within nephrology training such as onco-nephrology, geriatric nephrology, nephron-pathology would attract internal medicine residents with varied background and interests to pursue a career in nephrology.

\section{PROPOSED STRATEGIES TO INCREASE THE NEPHROLOGY WORK FORCE}

a) Creating an integrated 5-year training program in Nephrology after completing medical school to dedicate towards learning Nephrology while learning the fundamentals of internal medicine.

b) Family medicine/Family practice residents should be allowed to apply for Nephrology fellowship. If these residents are allowed to apply for Nephrology fellowship the number of applications can increase and thus it will increase the Nephrology work force.

c) Creating mini-fellowship in dialysis therapy (Peritoneal or hemodialysis)

A sad but potential outcome of this dwindling workforce could lead to losing the importance of the field in future. Nephrology may get divided and integrated amongst other sub-specialties such as Critical Care Nephrology with Critical Care fellowship, Diabetic nephropathy and other endocrine diseases with Endocrinology fellowship, Autoimmune disorders and vasculitides with Rheumatology fellowship and so on and so forth. Unless the current leadership takes an active interest and implement new strategies to ignite interest in nephrology, the future of nephrology appears to be in danger.

\section{CONFLICT OF INTEREST}

The authors confirm that this article content has no conflict of interest.

\section{ACKNOWLEDGEMENTS}

The author acknowledges that Dr. Lloyd Vincent, Head of Dept of Nephrology, Narayana Hrudayalaya Multispecialty hospital has helped in reviewing the manuscript.

\section{REFERENCES}

[1] Parker MG, Ibrahim T, Shaffer R, et al. The future nephrology workforce: will there be one? Clin J Am Soc Nephrol [Internet]. 2011 Jun [cited 2014 Jul 7]; 6(6): 1501-6. Available from: http://www.ncbi.nlm.nih.gov/pubmed/21551020

[2] McMahon GM, Thomas L, Tucker JK, et al. Factors in career choice among US nephrologists. Clin J Am Soc Nephrol [Internet]. 2012 Nov [cited 2014 Jul 7]; 7(11): 1786-92. Available from: http://www.pubmedcentral.nih.gov/articlerender.fcgi?artid=348894 7\&tool=pmcentrez\&rendertype $=$ abstract

[3] Parker MG, Pivert KA, Ibrahim T, et al. Recruiting the next generation of nephrologists. Adv Chronic Kidney Dis [Internet]. 2013 Jul [cited 2014 Jul 7]; 20(4): 326-35. Available from: http://www.ncbi.nlm.nih.gov/pubmed/23809285

[4] Desai T. Common sense ideas to increase the percentage of filled seats in nephrology fellowships. F1000Research [Internet]. 2014 Jan 6 [cited 2014 Jul 7]; 3: 3-7. Available from: http://f1000research.com/articles/3-3/v1 